\title{
Reasons of Individuals to Trust What They Read on Social Network Sites
}

\author{
Tom Sander ${ }^{1(凶)}$ and Phoey Lee Teh $^{2}$ \\ 1 Mannheim, Germany \\ 2 Sunway University, Subang Jaya, Malaysia \\ phoeyleet asunway. edu.my
}

\begin{abstract}
The rationality of believing a piece of information depends on the level of trust of each individual. To make a purchase decision, an individual has to trust the information they have collected from social media content. That said, to influence an individual's decision, companies have to obtain an individual's trust successfully. This study aims to investigate what makes an individual trust what they read on social media (SM). Participants of this study are from Germany and United Kingdom (UK). A model is created and tested with regression analysis. That helps to identify the impact experience with social network sites (SNSs) on trust of information in SNSs. The practical outcome is to provide advice to companies whereby to communicate with potential clients to transfer their information successfully and trustworthy.
\end{abstract}

Keywords: Trust $\cdot$ Social media $\cdot$ Content $\cdot$ Signaling theory $\cdot$ Digital networks

\section{Introduction}

Communication is an essential part of our daily life. Individuals communicate to convey knowledge and experience they gained from the information they read. Consider this, to successfully influence consumer's purchase decision; communication has to be in place beforehand. The objective is to send the most suitable information, with the most significant impact to the right target group. So that individuals able to apply for a role or decide to buy a product [1]. SM offers many opportunities to transfer information economically, with a small budget and low efforts compared with other channels. However, are those information posted appreciated? The difficulty is to ensure people able to trust SM information, which may reduce the value of social networks [2] for companies.

The privacy of individuals needs to be protected and user of SNSs open part of their privacy. They resist to use SNSs because their privacy is damaged and their data is misused. Companies violate the privacy in SM [3]. Analyze tools enable companies to explore the private life of SNSs members and to misuse this data for marketing purposes. That influence the acceptability as an information channel. Some people used SNSs as an informal communication channel and companies have had access to the communication and exchanged information. The user resist to use SNS to exchange information. The user reduce the access to information because they leave SNSs [4]. They do not share 
anymore critical or private information with other members, this study aims to find out what may affect others to trust the SM content that were privately shared.

The experience with content shared in SM platforms can be a reason for an individual to evaluate that the information posted online as unreliable, or rate SM as untrustworthy. The misuse of SM messages from criminals' group can damage the experience of an individual. Especially in the case when financial information is involved during the process. Journalists have been reporting about negative situations and fake news [5], which advice individuals to be more careful online [6]. Miscommunication of information could lead an individual to find this communication channel less valuable, and hence not to trust the information they have read [7]. This situation can cause a particular impact on companies financially. The impact of SM on our daily life is important. The technical opportunities and behavior of SM user influence the trust in SM. The value of $\mathrm{SM}$ is the transfer of information fast and easily between individuals [8]. Individuals can collaborate on various topics and develop new ideas. That support individuals in their future, to develop skills and to improve results of projects e.g. marketing or developing innovative products. That is only possible with trust in the provided information in SNSs [9]. The access to resources and maintenance of relationships is important asset of SNSs. SNSs are communities, electronic networks or organized groups which are connected with ties [10]. In this case, the most popular SNSs are LinkedIn or Facebook [11].

People needs to trust the information and use the information for their decision. Individuals get daily fake news, spam messages and phishing e-mails. This has a heavy influence on individuals in their daily use of SM information and damage the value of this communication tool [12]. Companies are under pressure to identify reasons that influence the trust of individuals in SM content. The government and society can be damaged if people following fake information. In crisis situation, particularly important that people able to trust information to decrease the negative impact on society. A good example is to trust the online information overlying the message that to stay at home is able to stop the spread of Coronavirus during the pandemic.

So, what makes an individual trust what they read on SNSs? The authenticity of a piece of information was said to depend on the reputation of the publisher. The reputation status of a publisher is reflected via the number of followers [13]. The more the follower, the higher the number of visibilities on that piece of said information [14]. This scenario allows for broader access to the target group and more extensive involvement from different stakeholders.

Experience determines epistemic trust [15]. If once have a positive experience in trusting a piece of information, they will return to the same source. Vice versa, if they have a negative experience, they will avoid to source information from the same channel. For instance, if a product was recommended to be good online, and individual that received the same good experience with the said product will later, be encouraged the returning to the same dealer [16]. The same person that is posting the same positive information leading on a specific product/organization on the same channel, and creating a line of the follower. They are an influencer, who then lead the follower to excellent access to additional and exclusive information [17].

On top of knowing someone virtually, individuals that have also known a person or have previously established relationship physically would also affect the trust [18]. 
The social tie is more durable; therefore, the faith is more substantial. The anonymity is in reality less compared to virtual environments [19]. It is fair to say that marketing commonly presents its products or services in a very positive manner [20]. Hence, information that comes from the social network can be more sensible compared to companies. The authenticity of the information is higher than other sources, and therefore, less doubt on the information presented [21].

The research has been done in UK and Germany. There are differences between countries in the use of SNSs. International companies need global solutions and need to understand their customer in different locations [22]. The research is concentrating on Germany and UK but further countries need to take under consideration to provide a deeper insight and to provide a global answer.

This paper is organized as follows. The Signaling theory is presented in next section. Section 3 present the model and analyses the social demographic of the participants. Section 4 and 5 are results obtained from German and UK participants respectively. Section 6 presents the regression analysis for all the items discussed relevant to signaling theory and end with the conclusion.

\section{Signaling Theory}

The signaling theory is a prominent theory to explain the transfer of information. The kind of signal needs to be transferred between individuals and the signal needs to have a value for the participants of the communication, that the individuals take part in the communication [23]. The knowledge which is gained by the information can be important to make a good decision, and cost saving. A typical example is the reason to employ an individual grounded on the collected signals which are later to be transferred in the Curriculum Vitae (CV) in the requirement process or during an interview [24]. SM increase the level of personal information to be observed as a signal to the users. The signal such as body language can be observed through video conference, but not in phone call.

Signal is referring to the idea that one credible party trying to convey some information about something to a receiver. The signal is used to make a decision. The most famous example of a scenario to explain this is through the process of purchasing a second hand used car. The sales person has more knowledge about the conditions of the car e.g. former damages of the car from an accident or experience in negotiation about a price for a car. The sales person can choose to hide negative information and to transfer only positive signal to the buyer. That is the advantage of signal received by the sales person against the buyer [25]. This information is named as "economical" benefit. This situation is mentioned in the literature as transaction cost [24]. The value of the information can be explained with the exclusivity of a piece of information that is not freely available from other resources (e.g.: SM). For instance, to obtained the information from purchasing it from a broker, which in this case, can be more expensive comparing to information that can be obtained from SNSs [26].

SNSs are social networks in the internet, on a technical basis. If you are not a member in the social network, you would not be able to expose any signal and send to other individual. People are connecting to SM through posting from each other to 
obtain information. Information is easily convey globally to a large audience on a low level of cost. A typical example from Sobel are about the diamond sellers who exchange diamonds for million of Euros without any guarantee. They take part in the exchange because they are part of a social network with their rules and agreements, that the member of the network would trust each other [27]. Trust is created with experience and based on expectations that were previously fulfilled [18]. This processes are also explained with the social capital theory, that people can increase their social capital with their knowledge [28]. The explanation of the value of the signal in SNSs is influenced by the social capital. As a consequence, this study aims to find out if the investment on SNSs (e.g.: time spend on the SM, the number of contact they have in their network) can affect the trust from other parties.

\section{Model and Method}

The model for this research paper has the dependent variable "trust" and the independent variable "use of SNSs" to explain the influence of the use of SNSs to trust or not to trust information on SNSs. The regression analysis test the impact of use of SNSs on the trust in information in SNSs. The expectation and hypothesis is that the intensive use of SNSs has a positive value on the trust of information in SNSs. That the trust in information in SNSs depends on the use of SNSs. The intensive trust develops skills to evaluate information in SNSs about their trustfulness and experience influence the trust in the information at SNSs [29]. That people with more experience and higher intensive use of SNSs have a higher level of trust in SNSs information [30]. That would explain the extensive use of SNSs as it provides a value to the intensive user.

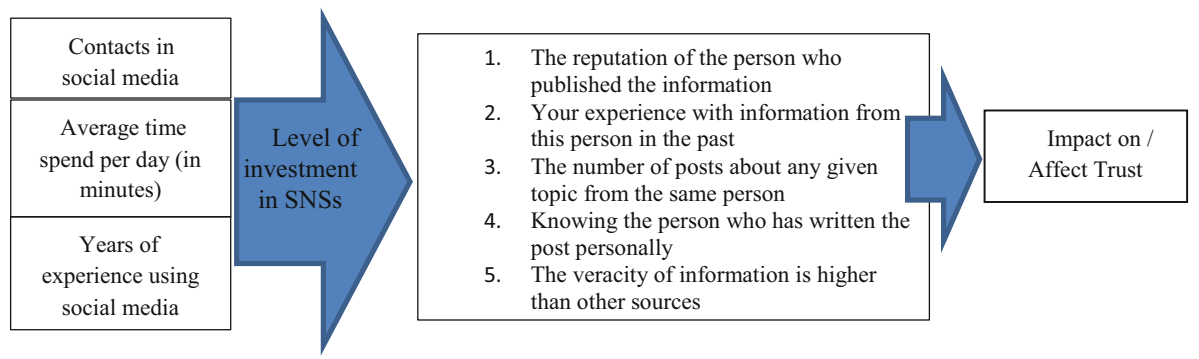

Fig. 1. Impact of investments in social network sites on factors which affect trust on information in SNSs

The independent variables on the left hand side of the model in figure one describe the individual's investment (e.g.: time, duration and years of experience) in SNSs. Box in the middle describe the 5 dependent variables to the question of "What makes you trust what you read on SNS?". These dependent variables are signals from each individuals in SNSs. This signals are convey to other SNSs members. These signals have an impact on individual's trust on information in SNSs.

In general, the model explains that the investment (e.g.: contact in SM, average in time spend per day and years of experience using SM) has an impact on the reason 
which makes individuals to trust what they read on SNSs. The result explains the reason to trust somebody in SNSs affect the trust on information in SNSs. This study has been done with an online survey due to the fact that the research field is online related and participants are expected to be part of the user of SNSs that have access to the internet, which can be cost effective and efficient [31]. The data has been collected between November and December 2018. The questionnaire was designed in both German and English languages.

The demographic factors of the participants is presented in Table 1. Up to 56 British participants and up to 144 German individuals take part in the survey.

Table 1. Demographic data of the participants of the survey UK n 46-49, German n 133-136

\begin{tabular}{l|l|l|l|l|l|l}
\hline Age in years & UK sample & $\begin{array}{l}\text { German } \\
\text { sample }\end{array}$ & & Social status & UK sample & $\begin{array}{l}\text { German } \\
\text { sample }\end{array}$ \\
\hline Mean & 33.9 & 34.07 & & Employed & $78.26 \%$ & $72.93 \%$ \\
\hline Std Dev. & 9.31 & 11.3 & & Unemployed & $2.17 \%$ & $21.80 \%$ \\
\hline Minimum & 18 & 18 & & Student & $8.70 \%$ & $0.75 \%$ \\
\hline Maximum & 56 & 69 & & Self employed & $10.87 \%$ & $4.51 \%$ \\
\hline Median & 32 & 33 & & & & \\
\hline Male & $51.02 \%$ & $44.12 \%$ & Gender & Female & $48.98 \%$ & $55.88 \%$ \\
\hline
\end{tabular}

The use of SNSs is defined with the duration of membership in years, number of contacts and time spend per day in average per minutes [32]. The details are presented in Table 2.

Table 2. Indicators of the use of SNS - number of contacts, duration of membership and time of use in minutes per day, German and UK sample

\begin{tabular}{l|r|r|r|l|l|c}
\hline & N & \multicolumn{1}{l|}{ Mean } & Std. Dev. & Min & Max & Median \\
\hline Contacts in SM - Germany & 137 & 594.38 & 1171.34 & 0 & 10000 & 250 \\
\hline $\begin{array}{l}\text { Average time spend per day (in minutes) - } \\
\text { Germany }\end{array}$ & 137 & 45.88 & 59.29 & 0 & 360 & 30 \\
\hline Years of experience using SM - Germany & 137 & 6.55 & 4.02 & 0 & 15 & 7 \\
\hline Contacts in SM - UK & 49 & 660.22 & 635.42 & 2 & 3500 & 500 \\
\hline $\begin{array}{l}\text { Average time spend per day (in minutes) - } \\
\text { UK }\end{array}$ & 49 & 59.73 & 66.78 & 2 & 300 & 30 \\
\hline Years of experience using SM - UK & 49 & 8.71 & 2.89 & 2 & 15 & 8 \\
\hline
\end{tabular}

The data is analyzed with descriptive statistic e.g. mean, standard deviation, median and mode. Further is the data analyzed with an ANOVA and tested with T-test for gender 
differences. The fit of the model is analyzed with regression analysis. The main focus of the paper is on the model calculated with a regression analysis to explain the influence of use of SNSs on the trust in information on SNSs [33].

\section{Results for the German Sample}

The descriptive statistic provides a first overview about the factors and described in detail below. The most positive influence on trust has the item G4. This is an interesting point that the real social network and reality has a large influence on individuals. That influencer and companies need to get in touch on various level with customer to improve the trust level. The lowest influence on the trust in the information has the item G5 with a mode of six and median of five. The expectation to get a more veracity of information, to get the reality from another perspective to increase the reality is not a reason to trust the results more compared with other items. A tendency to a positive influence on the trust is the experience with the information from an individual. That means to publish wrong information or fake information has a negative impact on trust in information on future messages. The result for the item G2 has a median of three and mode of three. The reputation of the person who post the information has a median and mode of four (item G1). The number of posts is not deeply relevant that people from Germany do not trust information in SNSs (item G3). It appears that the number of posts is not relevant for the trust level in a negative or positive way.

Table 3. "What makes you trust what you read on SNS?", German sample, 1 for strongly agree to 6 for strongly disagree

\begin{tabular}{l|l|l|l|l|l}
\hline ID & Item & $\mathrm{N}$ & Mode & Std. Dev. & Median \\
\hline G1 & $\begin{array}{l}\text { The reputation of the person who published the } \\
\text { information }\end{array}$ & 143 & 4 & 1.46 & 4 \\
\hline G2 & $\begin{array}{l}\text { Your experience with information from this person } \\
\text { in the past }\end{array}$ & 141 & 3 & 1.46 & 3 \\
\hline G3 & $\begin{array}{l}\text { The number of posts about any given topic from the } \\
\text { same person }\end{array}$ & 141 & 6 & 1.38 & 4 \\
\hline G4 & $\begin{array}{l}\text { Knowing the person who has written the post } \\
\text { personally }\end{array}$ & 144 & 2 & 1.68 & 3 \\
\hline G5 & $\begin{array}{l}\text { The veracity of information is higher than other } \\
\text { sources }\end{array}$ & 143 & 6 & 1.29 & 5 \\
\hline
\end{tabular}

It does not exist a statistical significant relevant difference for the explored items between the answers of men and women for the German sample. That has been tested with a t-test. 


\section{Results for the English Sample}

The response from the participants from the UK have a higher tendency to strongly agree. The item E1, E2 and E4 have median and mode two. On the other side of the scale to strongly disagree with median and mode four are the items E3 and E5. That means there are two groups of items with different impact on the trust level for information.

Table 4. "What makes you trust what you read on SNS?", UK sample, 1 for strongly agree to 6 for strongly disagree

\begin{tabular}{l|l|l|l|l|l}
\hline ID & Item & $\mathrm{N}$ & Mode & Std. Dev. & Median \\
\hline E1 & $\begin{array}{l}\text { The reputation of the person who published the } \\
\text { information }\end{array}$ & 56 & 2 & 1.31 & 2 \\
\hline E2 & $\begin{array}{l}\text { Your experience with information from this person in the } \\
\text { past }\end{array}$ & 56 & 2 & 1.29 & 2 \\
\hline E3 & $\begin{array}{l}\text { The number of posts about any given topic from the same } \\
\text { person }\end{array}$ & 56 & 4 & 1.3 & 4 \\
\hline E4 & Knowing the person who has written the post personally & 55 & 2 & 1.58 & 2 \\
\hline E5 & The veracity of information is higher than other sources & 55 & 4 & 1.46 & 4 \\
\hline
\end{tabular}

The descriptive statistic results is strongly supported by the distribution of the answer of the British participants.

It does not exist a statistical significant difference for the explored items between the answers of men and women for the English sample. That has been tested with a t-test.

\section{Results of the Regression Analysis}

This section present the results of the regression analysis. The concept is that individuals who use the SNSs intensive use the information and trust the information in a different way compared with individuals who use the social network less intensive. The intensity of use is described with duration of membership in years, number of contacts and how many minutes per day individuals use SNSs. The regression analysis test the impact of the use of SNSs information. That heavy SNS user have a different anticipation of information compared with normal SNSs user.

$\mathrm{R}^{2}$ is measurable but on a weak and different level depending on the trust variable G1-G5. There are four items with a significant result (tested with ANOVA) The highest $\mathrm{R}^{2}$ is scored by item $\mathrm{G} 3$, it shown that the independent variables explain best the item G3. That the prediction of the trust is possible with the use of SNSs. Follow by G2 and G5 with the result 0.11 for $\mathrm{R}^{2}$. That the trust in information is predictable with the use of SNSs. The weakest statistically significant result has with the item G1 is 0.09 for $\mathrm{R}^{2}$. The use of SNSs can explain the level of trust in information from SNSs with different strong impact. The results for the model with the indicators for trust are presented in Table 5. 
Table 5. Results of the regression analysis for the German sample

\begin{tabular}{l|l|l|l|l|l}
\hline ID & Item & $\mathrm{R}$ & R-Square & Corrected R - Square & $\begin{array}{l}\text { Standard error of the } \\
\text { estimate }\end{array}$ \\
\hline $\mathrm{G1}$ & $\begin{array}{l}\text { The reputation of the } \\
\text { person who published } \\
\text { the information }\end{array}$ & 0.29 & 0.09 & 0.06 & 1.43 \\
\hline $\mathrm{G} 2$ & $\begin{array}{l}\text { Your experience with } \\
\text { information from this } \\
\text { person in the past }\end{array}$ & 0.34 & 0.11 & 0.09 & 0.34 \\
\hline G3 & $\begin{array}{l}\text { The number of posts } \\
\text { about any given topic } \\
\text { from the same person }\end{array}$ & 0.42 & 0.17 & 0.15 & 1.27 \\
\hline G4 & $\begin{array}{l}\text { Knowing the person } \\
\text { who has written the } \\
\text { post personally }\end{array}$ & 0.25 & 0.06 & 0.03 & 1.64 \\
\hline G5 & $\begin{array}{l}\text { The veracity of } \\
\text { information is higher } \\
\text { than other sources }\end{array}$ & 0.33 & 0.11 & 0.08 & 1.24 \\
\hline
\end{tabular}

The item G4 with the strongest tendency to fully agreement is not statistically significant for the regression analysis and has the lowest $\mathrm{R}^{2}$. That means the impact of the intensity of use of SNS is on a low level. There is some influence but further research needs to find more variables and items to explain the trust in information from SNSs.

The corrected $\mathrm{r}$ - square is very low, the determination is weak and it is not on a statistical accepted scientific significant level (tested with ANOVA). That means the investment on SNSs does not impact the indicators from E1-E5.

The last tables provide the full picture of the results of the investigation but the results cannot be used for any explanation. That mean comments regarding the UK model cannot be done on a serious scientific level with this results. 
Table 6. Results of the regression analysis for the UK sample

\begin{tabular}{l|l|l|l|l|l}
\hline ID & Item & $\mathrm{R}$ & $\mathrm{R}$-Square & Corrected R - Square & $\begin{array}{l}\text { Standard error of the } \\
\text { estimate }\end{array}$ \\
\hline E1 & $\begin{array}{l}\text { The reputation of the } \\
\text { person who published } \\
\text { the information }\end{array}$ & 0.24 & 0.06 & -0.03 & 1.08 \\
\hline E2 & $\begin{array}{l}\text { Your experience with } \\
\text { information from this } \\
\text { person in the past }\end{array}$ & 0.17 & 0.03 & -0.06 & 1.11 \\
\hline E3 & $\begin{array}{l}\text { The number of posts } \\
\text { about any given topic } \\
\text { from the same person }\end{array}$ & 0.25 & 0.06 & -0.03 & 1.36 \\
\hline E4 & $\begin{array}{l}\text { Knowing the person } \\
\text { who has written the } \\
\text { post personally }\end{array}$ & 0.37 & 0.14 & 0.05 & 1.43 \\
\hline E5 & $\begin{array}{l}\text { The veracity of } \\
\text { information is higher } \\
\text { than other sources }\end{array}$ & 0.33 & 0.11 & 0.02 & 1.34 \\
\hline
\end{tabular}

\section{Conclusion}

As a conclusion, the acceptance of information depends on the signal a person holds, which are affected by the environment, situation and person who presents the information. To summarize, there are two items that are highly responsible in influencing the trust of a piece of information. These two items are firstly refer to the frequency of exposure on a same piece of information and secondly, personal experience or knowing the person in real life.

Specifically, German show higher needs in having various experiences in order to trust a piece of information. British participants, however, rated less. Reputation is more important factor that influence the trust for UK participants.

The results for the regression analysis for the German items is statistic significant but the results for the UK is not on a statistic relevant significant level. There is no significant relevant answer for the UK sample regarding the model.

The results of $\mathrm{R}^{2}$ is not for all items for Germany on a statistical relevant level and the $\mathrm{R}^{2}$ is on a low level. The power of the impact of the independent variable on the dependent variables are weak. The regression analysis provides the feedback that the use of SNSs has influence on the trust in SNSs in Germany. The majority of the items can be explained with the intensity of use. The intensity of use is defined with the user's invested in SNSs. That is important to cluster user of SNSs to provide the best solution e.g. information on a regular basis to create trust, that the individual get experience. The only item without a statistical significant level result is "Knowing the person who has written the post personally". That means that the use of SNSs influence the reason to believe information on SNSs. 
Further research needs to explore more countries and items to provide more support to the business to decide how to make valuable communication and sending signals to the audience which are used, trusted and accepted.

\section{References}

1. Ferreira, A., Antunes, F.: Essential functionalities for commercial internet presence. Int. J. E-bus. Res. 11(1), 56-83 (2015)

2. Li, C., Bernoff, J.: Groundswell, Winning in a World Transformed By Social Technologies. Harvard Business Review Press, Boston (2011)

3. Conde, M.Á., Fonseca, D.: Information society skills: is knowledge accessible for all? Part I. Univ. Access Inf. Soc. 17(2), 223-227 (2018)

4. Fonseca, D., Conde, M.Á.: Information society skills: is knowledge accessible for all? Part II. Univers. Access Inf. Soc. 17(3), 447-451 (2018)

5. Ross, A.S., Rivers, D.J.: Discursive deflection : accusation of 'fake news' and the spread of mis- and disinformation in the tweets of president Trump. Soc. Media + Soc. 4, 1-12 (2018)

6. Bakir, V., McStay, A.: Fake news and the economy of emotions: problems, causes, solutions. Digit. J. 0811, 1-22 (2017)

7. Turcotte, J., York, C., Irving, J., Scholl, R.M., Pingree, R.J.: News recommendations from social media opinion leaders: effects on media trust and information seeking. J. Comput. Commun. 20(5), 520-535 (2015)

8. Hemsley, J., Jacobson, J., Gruzd, A., Mai, P.: Social media for social good or evil : an introduction. Soc. Media + Soc. 4, 1-5 (2018)

9. Tsai, C.W.: Applications of social networking for universal access in online learning environments. Univers. Access Inf. Soc. 16(2), 269-272 (2017)

10. Calero Valdez, A., Brell, J., Schaar, A.K., Ziefle, M.: The diversity of why: a meta-analytical study of usage motivation in enterprise social networks. Univers. Access Inf. Soc. 17(3), 549-566 (2018)

11. Ellison, N.B., Steinfield, C., Lampe, C.: The benefits of Facebook 'friends:' social capital and college students' use of online social network sites. J. Comput. Mediat. Commun. 12, 1143-1168 (2007)

12. Simeone, M., Russo, C.: The growing influence of social and digital media. Br. Food J. 119(8), 1766-1780 (2017)

13. Stenger, T.: Social media and online reputation management as practice: first steps towards social CRM? Int. J. Technol. Hum. Interact. 10(4), 49-64 (2014)

14. Maras, M.: The economic costs and consequences of mass communications data retention: is the data retention directive a proportionate measure? Eur. J. Law Econ. 33, 447-472 (2012)

15. Wang, C., Chen, C., Chen, C.: Exploring the different aspects of internet leisure use by college students. Inf. Dev. 31(1), 5-12 (2015)

16. Rezaei, S., Ismail, W.K.W.: Examining online channel selection behaviour among social media shoppers: a PLS analysis. Int. J. Electron. Mark. Retail. 6(1), 28 (2014)

17. Gillin, P.: New media, new influencers and implications for the public relations profession. J. New Commun. Res. II(2), 1-0 (2008)

18. Pruijt, H.: Social capital and the equalizing potential of the internet. Soc. Sci. Comput. Rev. 20(2), 109-115 (2002)

19. Wellman, B., Boase, J., Chen, W.: The networked nature of community online and offline. IT Soc. 1(1), 151-165 (2002)

20. Bernoff, J., Schadler, T.: Empowered. Harvard Business Review Press, Boston (2010) 
21. Kim, J., Lee, C., Elias, T.: Factors affecting information sharing in social networking sites amongst university students. Online Inf. Rev. 39(3), 290-309 (2015)

22. Sander, T., Sloka, B., Puke, I.: Differences in the exchange of contents of different countries in social network sites. Int. J. E-colaboration 13(2), 17 (2017)

23. Spence, M.: Job market signaling. Q. J. Econ. 87, 355-374 (1973)

24. Fussell, H., Harrison-Rexrode, J., Kennan, W.R., Hazleton, V.: The relationship between social capital, transaction costs, and organizational outcomes: a case study. Corp. Commun. Int. J. 11(2), 148-161 (2006)

25. Emons, W., Sheldon, G.: The market for used cars: new evidence of the lemons phenomenon. Appl. Econ. 41 (2007)

26. Arvidsson, A.: Speaking out: the ethical economy: new forms of value in the information society? Organization 17(5), 637-644 (2010)

27. Sobel, J.: Can we trust social capital? J. Econ. Lit. XL, 139-154 (2002)

28. Behtoui, A.: Beyond social ties: the impact of social capital on labour market outcomes for young Swedish people. J. Sociol. 50(1), 1-14 (2015)

29. Nelmapius, A., Boshoff, C.: A motivational perspective on the user acceptance of social media. South Afr. J. Bus. Manag. 47(4), 1-3 (2016)

30. Sander, T., Teh, P.L.: Is social media changing the awareness of individuals? In: International Conference on New Trends in Social Sciences (2017)

31. Evans, J.R., Mathur, A.: The value of online surveys. Internet Res. 15(2), 195-219 (2005)

32. John, R.B.A., Lucila, O.B.: Personality traits as predictors of Facebook use. Int. J. Psychol. Couns. 8(4), 45-52 (2016)

33. Rosopa, P.J., Kim, B.: Robustness of statistical inferences using linear models with metaanalytic correlation matrices. Hum. Resour. Manag. Rev. 27(1), 216-236 (2017) 